\title{
Study on the Operation Effect of Constructed Wetland Project for Tailwater Treatment-An Example from a Sewage Plant in Zhejiang Province
}

\author{
Mengyin Chen ${ }^{1,2,3}{ }^{*}$, Weifeng Zeng ${ }^{1,2,}$, Guan Wang ${ }^{1,2}$ Fangchun Lu ${ }^{1,2}$, Jinjuan Zhang ${ }^{1,2}$, and Jianhua Ding ${ }^{1,2}$ \\ ${ }^{1}$ Zhejiang Guangchuan Engineering Consulting Co. Ltd., Hangzhou, Zhejiang 310020, China \\ ${ }^{2}$ Zhejiang Institute of Hydraulics and Estuary, Hangzhou, Zhejiang 310020, China \\ ${ }^{3}$ Zhejiang Key Laboratory of Water Disaster Prevention and Reduction, Hangzhou 310020, China
}

\begin{abstract}
The constructed wetland project of tailwater from an urban sewage plant in central Zhejiang was selected to collect water samples in different seasons, and the samples were tested for chemical oxygen demand (COD), total phosphorus (TP), total nitrogen (TN) and other indicators. The results showed that the operation effect of the constructed wetland project is good when the effluent from the sewage treatment plant meets the Class A discharge standard. Among them, the removal effect of TP was the best, with an average removal rate of $61.52 \%$, reaching the standards of surface water class III and class IV in some tests. Besides, the removal effect of TP was stable and varies little with seasons. The removal rates of COD and $\mathrm{TN}$ were relatively low and varied greatly with seasons, which were higher in spring and summer than in autumn and winter, with a negative removal rate of $\mathrm{TN}$ in winter. This research provides practical data for optimizing the engineering design parameters and improving the operation management to promote the operation efficiency of the constructed wetland.
\end{abstract}

\section{Introduction}

With the development of China's economy and the acceleration of urbanization in recent years, the amount of wastewater discharge has increased dramatically, China's total wastewater discharge reached 75 billion tons in $2018^{[1]}$, and the wastewater is finally discharged into natural water body after treatment. There is still a big gap between the current tailwater discharge standards of China's sewage treatment plants and the environmental quality standards of surface water. A large discharge volume of sewage treatment plants with a high concentration of nitrogen and phosphorus is likely to cause eutrophication of the receiving water bodys ${ }^{[2]}$. Therefore, advanced treatment of the tailwater of the sewage treatment plant is needed. Constructed wetlands are widely used in the tailwater treatment of sewage treatment plants especially in small-town due to the characteristics of impact resistance, easy maintenance, low initial investment, low operation and maintenance $\operatorname{costs}^{[3-5]}$. However, as the biological treatment mechanism of constructed wetlands, the design parameters of constructed wetlands cannot be accurate. More than this, the effluent quality fluctuates greatly due to the influence of environmental conditions, even becoming a new pollution source under certain conditions ${ }^{[11]}$. This paper intends to provide a reference for the design and operation management of the constructed wetland project by studying the actual operation effect, seasonal differences and influencing factors of the tailwater constructed wetland project of the sewage treatment plant, in order to optimize the design and application of the constructed wetland project and enhance the actual operating efficiency.

\section{Project overview}

The constructed wetland project selected in this study is located in a town in central Zhejiang province, with a subtropical monsoon climate. It is hot and humid in summer, and cold and dry in winter, with an average annual temperature of $17.2^{\circ} \mathrm{C}$ and an average annual rainfall of $1403.0 \mathrm{~mm}$.

The constructed wetland project is a deep treatment unit for the tailwater of a sewage plant. The sewage is a mixture of domestic sewage and industrial wastewater, in which industrial wastewater is $\sim 70 \%$. A process of 'aeration sedimentation tank + multi-modal of $\mathrm{A} / \mathrm{A} / \mathrm{O}+$ radial-flow sedimentation tank' was used and the effluent reached level A standard. The tailwater constructed wetland, which is multistage integrated, is composed of a bio-film system (integrated vertical flow units), surface flow constructed wetland, ecological ditch, and stable ponds, with a total area of $75567 \mathrm{~m}^{2}$. The designed water treatment capacity is $35000 \mathrm{~m}^{3} / \mathrm{d}$, with a total designed hydraulic retention time (HRT) of 2.15 days. Parameters of wetland units are shown in Table 1. The constructed wetland project was completed in

* Corresponding author: cmy881118@163.com 
December 2014, and trial operation began in the first half of 2015 .

Table 1. Parameters of wetland units.

\begin{tabular}{|c|c|c|c|c|}
\hline Units & $\begin{array}{c}\text { Effective } \\
\text { volume } \\
\left(\mathbf{m}^{3}\right)\end{array}$ & $\begin{array}{c}\text { Average } \\
\text { water depth } \\
\text { (m) }\end{array}$ & $\begin{array}{c}\text { HRT } \\
\text { (h) }\end{array}$ & $\begin{array}{l}\text { HLR } \\
\text { (m/d) }\end{array}$ \\
\hline $\begin{array}{l}\text { Multistage } \\
\text { bio-film } \\
\text { system }\end{array}$ & 7925 & 1.85 & 5.4 & 8.17 \\
\hline $\begin{array}{c}\text { Surface flow } \\
\text { wetland } \\
\text { system }\end{array}$ & 4550 & 0.35 & 3.1 & 2.69 \\
\hline $\begin{array}{c}\text { Ecological } \\
\text { ditch }\end{array}$ & 6972 & 1 & 4.8 & 5.02 \\
\hline $\begin{array}{c}\# \\
\text { stabilization } \\
\text { pond } \\
\end{array}$ & \multirow{3}{*}{55975} & 1.4 & \multirow{3}{*}{38.4} & \multirow{3}{*}{0.63} \\
\hline Artificial river & & 0.8 & & \\
\hline $\begin{array}{c}2 \# \\
\text { stabilization } \\
\text { pond } \\
\end{array}$ & & 1.4 & & \\
\hline
\end{tabular}

The tailwater of the sewage plant was transported into the constructed wetland system through pipelines. The effluent was discharged into a nearby water body after flowing through all the units by topographic height difference. The process flow of the constructed wetland is shown in Figure 1.

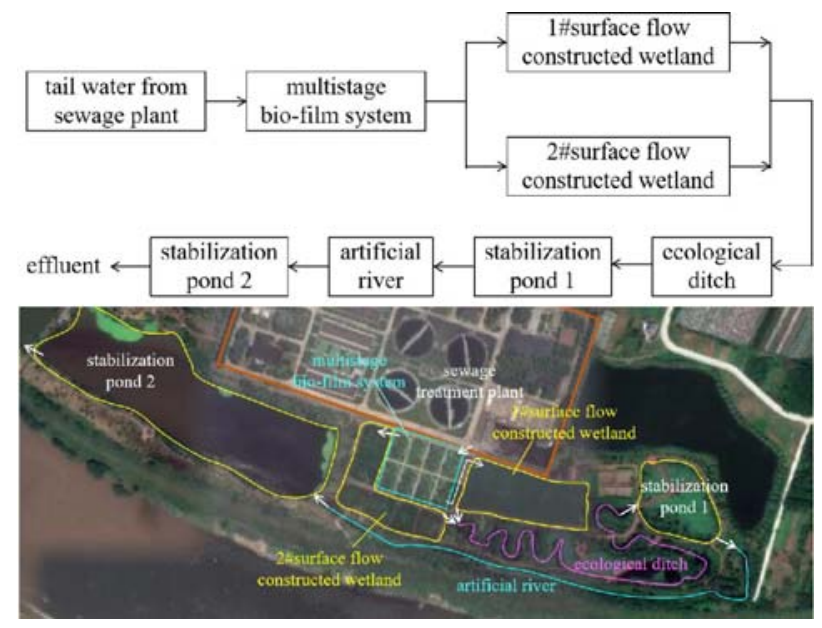

Fig. 1. The process flow and layout of the constructed wetland.

The multistage bio-film system, mainly composed of contact oxidation tanks, was potted with Thalia, Iris Pseudacorus Linn, and Lysimachia by a large area of floating islands in the upper part, and film-filling fillers attached in the middle and lower parts. The multistage bio-film system had two sets of parallel pools, and four pools were set in series for each group. The surface flow wetland system was divided into two groups operating in parallel, with one planting with Iris Pseudacorus Linn and the other with Pontederia cordata. The width of the ecological ditch was 4-6 m, submerged plants like Bittergrass and Elodea were planted at the bottom of the ditch, and aquatic animals such as river mussels and snails are stocked, with Iris Pseudacorus Linn, Canna and Pontederia Cordata planted on the slope.
The 1\# stabilization pond, artificial river, and 2\# stabilization pond run in series, with an average water depth of $1.4 \mathrm{~m}$, planted with Iris Pseudacorus Linn, Cattail, and Canna on the slope. The artificial river was 2-6 m in width, submerged plants Bittergrass and Elodea were planted at the bottom of the ditch, and aquatic animals such as river mussels and snails are stocked, with Iris Pseudacorus Linn, Canna and Pontederia cordata planted on the slope.

\section{Methods}

A total of 28 samples were collected at 7 sampling sites, including the inlet of the constructed wetland, the outlets of each unit along the constructed wetland, and the outlet of the constructed wetland in each quarter (Table 2).

Table 2. Location of sampling sites.

\begin{tabular}{|c|c|}
\hline Site number & Location \\
\hline 1 & $\begin{array}{c}\text { Inlet of the constructed wetland (Tailwater } \\
\text { outlet of sewage plant) }\end{array}$ \\
\hline 2 & Outlet of multistage bio-film system \\
\hline 3 & Outlet of the surface flow wetland system \\
\hline 4 & Outlet of ecological ditch \\
\hline 5 & Outlet of 1\# stabilization pond \\
\hline 6 & Outlet of artificial river \\
\hline 7 & Outlet of 2\# stabilization pond \\
\hline $\mathrm{pH}, \quad$ dissolved oxygen (DO), chemical oxygen
\end{tabular}
demand (COD), total nitrogen (TN) and total phosphorus (TP) were measured according to the standard method in $<$ Water and Wastewater Monitoring and Analysis Method $>(\text { Fourth Edition })^{[6]}$.

\section{Results and analysis}

\subsection{Inlet water quality}

Table 3. Inlet water quality of constructed wetland.

\begin{tabular}{|c|c|c|c|c|}
\hline $\begin{array}{c}\text { Sampling } \\
\text { time }\end{array}$ & 2016.04 & 2016.07 & 2016.10 & 2016.11 \\
\hline $\begin{array}{c}\text { Water } \\
\text { temperature } \\
\left({ }^{\circ} \mathbf{C}\right)\end{array}$ & 20.2 & 28.05 & 28.05 & 20.2 \\
\hline $\begin{array}{c}\mathbf{p H} \\
(\mathbf{m g} / \mathbf{L})\end{array}$ & 7.31 & 7.66 & 8.04 & 8.47 \\
\hline $\begin{array}{c}\mathbf{D O} \\
(\mathbf{m g} / \mathbf{L})\end{array}$ & 8.6 & 5.06 & 5.45 & 6.38 \\
\hline $\begin{array}{c}\mathbf{C O D} \\
(\mathbf{m g} / \mathbf{L})\end{array}$ & 33 & 43 & 40 & 49 \\
\hline $\begin{array}{c}\mathbf{N H}-\mathbf{N} \\
(\mathbf{m g} / \mathbf{L})\end{array}$ & 0.65 & 0.14 & 0.46 & 0.39 \\
\hline $\begin{array}{c}\mathbf{T N} \\
(\mathbf{m g} / \mathbf{L})\end{array}$ & 9.88 & 6.15 & 5.76 & 3.5 \\
\hline $\begin{array}{c}\mathbf{T P} \\
(\mathbf{m g} / \mathbf{L})\end{array}$ & 0.38 & 0.50 & 0.35 & 0.29 \\
\hline
\end{tabular}


The inlet water of the constructed wetland system is the tailwater of the sewage plant with water quality during the experiment shown in Table 3.

\subsection{Total removal efficiency}

Samples from the constructed wetland were analyzed quarterly. As shown in Figure 2, the constructed wetland had a certain effect on the removal of pollutants in the tailwater of the sewage plant, among which the removal rate of TP was the highest, followed by COD, while the removal rate of TN was relatively low.

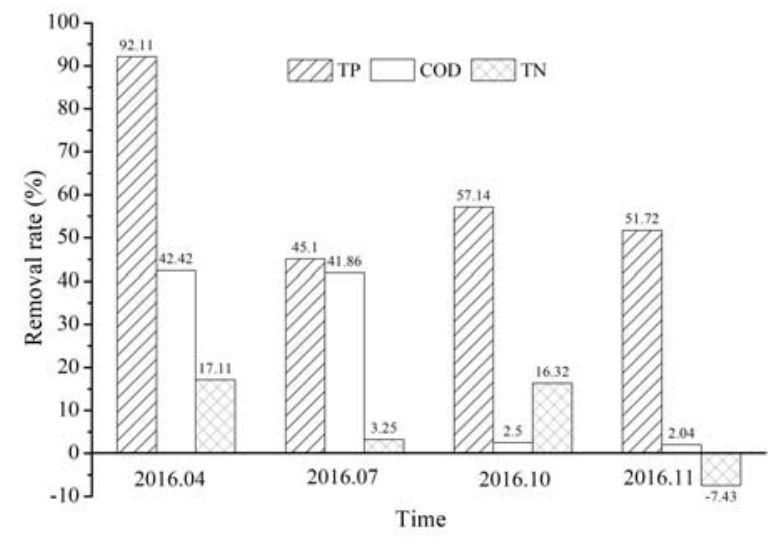

Fig. 2. The Removal rate of pollutants in the constructed wetland.

The average removal rate of TP in the constructed wetland was $61.5 \%$, with values higher than $45 \%$ in all four seasons and the highest of $92.1 \%$ in spring. The average removal rate of COD was $22.2 \%$, which was relatively high in spring and summer, with an average value of $42.1 \%$, while the removal rate in autumn and winter declined to an average value of $2.3 \%$. The average removal rate of TN was $7.3 \%$, with a negative removal rate in winter.

\subsection{Variations in environmental factors along wetlands}

\subsection{1 $\mathrm{pH}$}

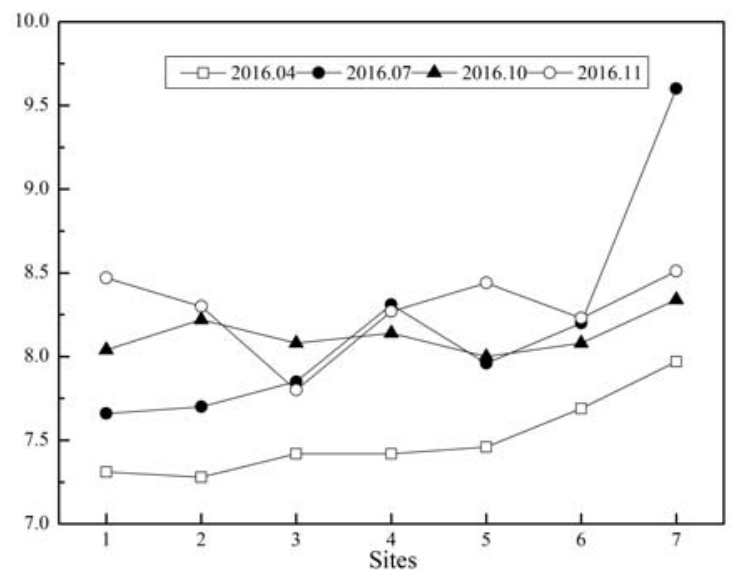

Fig. 3. Variations of $\mathrm{pH}$ along the wetland.
The $\mathrm{pH}$ of samples in spring and summer increased gradually from inlet to outlet, with values from 7.3 to 7.9 in April and from 7.6 to 8.6 in July (Figure 3). However, there was no significant upward trend of $\mathrm{pH}$ in October and November, fluctuating in the range of 7.8 to 8.5 .

\subsubsection{Dissolved oxygen}

The DO concentration of the tailwater decreased after flowing the multistage bio-film system and the surface flow wetland system, followed by an upward trend from the ecological ditch (Figure 4). Dissolved oxygen concentration in water from outlet was higher than that from inlet in 4 seasons, with the highest increase of $42.8 \%$, indicating that the constructed wetland can effectively increase the dissolved oxygen concentration in water.

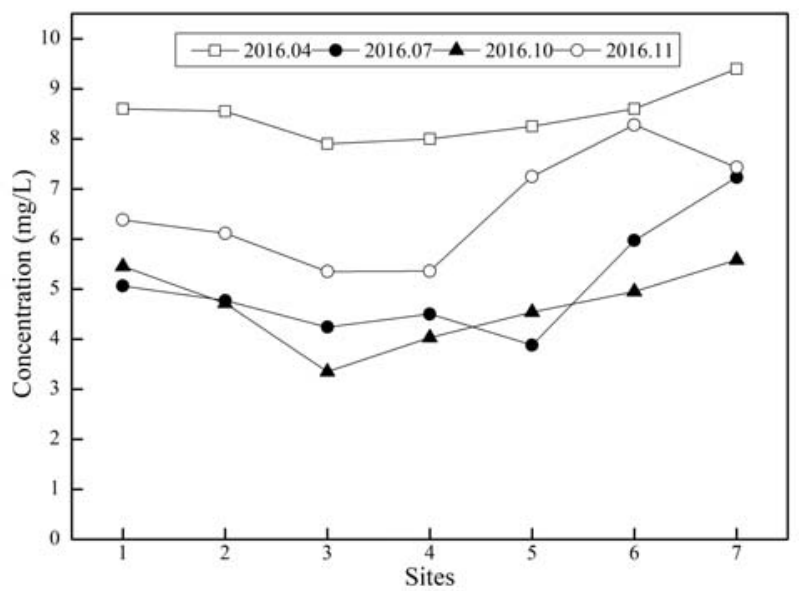

Fig. 4. Variations of the concentration of DO along the wetland.

\subsection{TN}

The TN concentration of the tailwater declined gradually from inlet to the outlet of the artificial river in April, while it increased after flowing the last unit 2\# stabilization pond (Figure 5). There was no significant trend of TN concentration from inlet to outlet in July, which fluctuated slightly within a certain range. In October, the TN concentration decreased from inlet to the outlet of surface flow wetland system gradually, and then increased after passing through the ecological ditch and $1 \#$ stabilization pond, and decreased again after entering the artificial river and $2 \#$ stabilization pond. The TN concentration increased along the way of the wetland to the $1 \#$ stabilization pond and then decreased in the artificial river in November. Overall, there was no significant variation trend of $\mathrm{TN}$ concentration along the wetland, with decreased values from inlet to outlet in the first three seasons. 


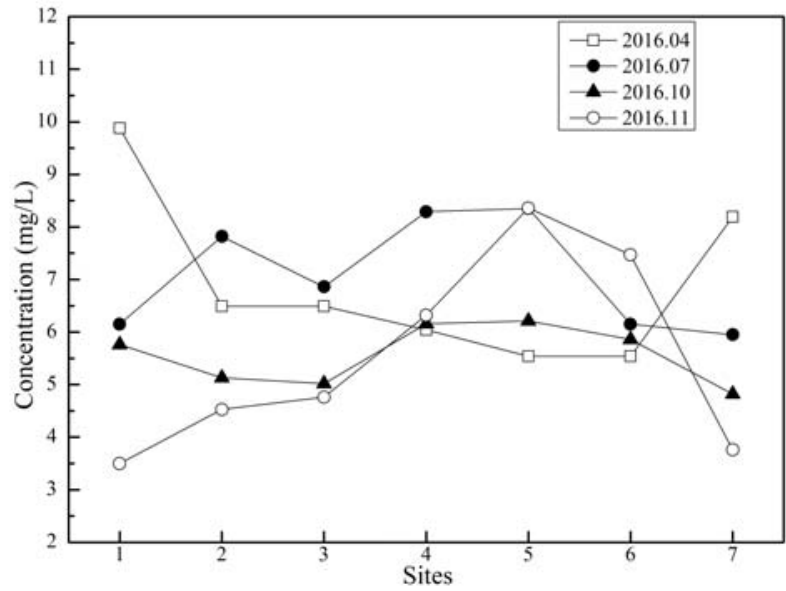

Fig. 5. Variations of the concentration of $\mathrm{TN}$ along the wetland.

\subsection{TP}

The concentration of TP of the tailwater decreased gradually along the inlet to the outlet generally in the constructed wetland in spring, summer, and autumn, while in winter, it decreased gradually from inlet to the outlet of the ecological ditch, and then increased gradually in the later units (Figure 6).

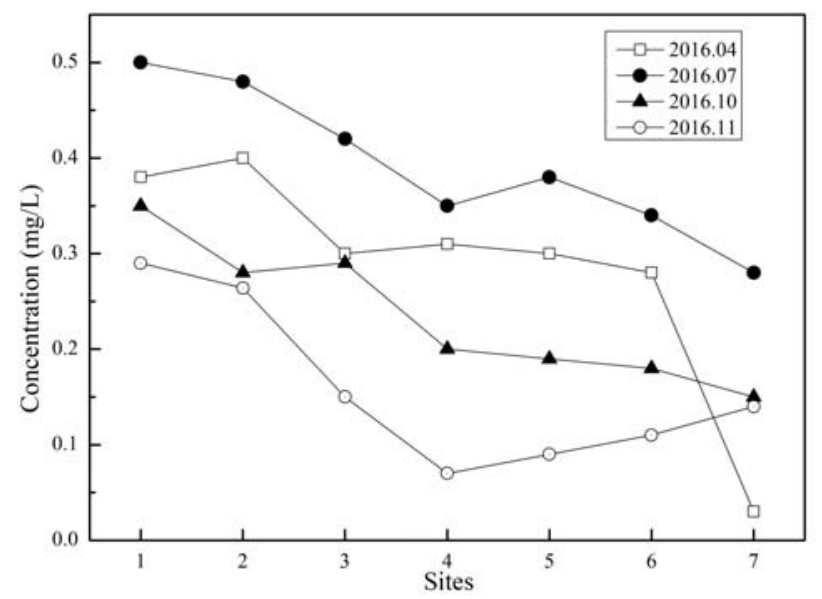

Fig. 6. Variations of the concentration of TP along the wetland.

\subsection{COD}

In spring and summer, the COD concentration of the tailwater decreased significantly despite slight fluctuations along the wetland, while in autumn and winter the COD concentration showed no obvious decreasing trend with fluctuation along the wetland (Figure 7).

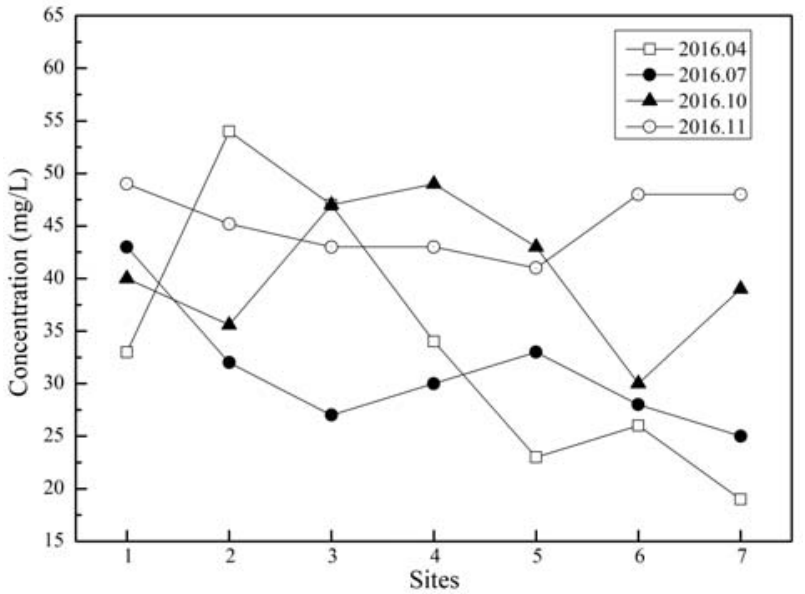

Fig. 7. Variations of the concentration of COD along the wetland.

\section{Discussion}

The removal of pollutants in a constructed wetland is mainly based on processes such as microbial action in the micro-environment of the plant root system and fill materials, substrate adsorption, and plant absorption ${ }^{[7]}$.

The constructed wetland in this study had an effective removal of $\mathrm{TP}$, with a high removal rate of $92.1 \%$ in spring. The removal of TP in wetlands is mainly taken through plant uptake, substrate adsorption, and microbial transformation. This constructed wetland is mainly composed of surface-flow wetlands, ecological ditches, and stabilization ponds, resulting in a high concentration of dissolved oxygen in the system, which is conducive to the adsorption of $\mathrm{P}$ by the substrate. Besides, the surface-flow wetland system was planted with a large amount of emerged plants in high biomass, they assimilate $\mathrm{P}$ for their growth in spring, which is beneficial to the removal of TP.

The removal of COD is more effective in spring and summer with an average removal rate of $42.1 \%$ than that in autumn and winter with an average removal rate of $22.2 \%$, which demonstrates significant seasonal influence on the removal of COD in this constructed wetland. Plants withered in fall and winter may release organic matters into the water in corruption, resulting in poorer COD removal in fall and winter than in spring and summer.

The removal rate of $\mathrm{TN}$ in this constructed wetland is relatively low, with an average value of less than $10 \%$ and negative in winter. Nitrogen removal in wetlands is mainly achieved through microbial action, plant uptake, and substrate adsorption, in which the nitrification and denitrification are considered to be the main pathways of nitrogen removal in wetlands and are one of the important causes of nitrogen $\operatorname{loss}^{[8-9]}$. Nitrification and denitrification are influenced by carbon source, dissolved oxygen concentration, $\mathrm{pH}$, and temperature in the wetland. Low $\mathrm{C} / \mathrm{N}$ ratio in the inlet water inhibits the TN removal in this constructed wetland. The denitrification requires an aerobic-anaerobic alternating environment, and the more homogeneous oxygen environment in this constructed wetland limits the 
progress of nitrification and denitrification. Temperature is of great importance on the nitrogen removal in constructed wetlands since microbial activities such as nitrification and denitrification are more sensitive to environmental temperature. In addition, the wilt of plants in the wetland will release rather than absorption and assimilate nitrogen to the wetland system in winter. The nitrogen decomposing slowed down due to reduced nitrification capability of the system caused by low temperature, leading to poor water quality or even higher nitrogen concentration in outlet water than the inlet water in winter.

The design and operation of the constructed wetland project are complicated and difficult to control, due to various factors affecting the operation effect. Thus, theoretical design parameters (including hydraulic load, hydraulic retention time, wetland area, plant configuration, etc.) should be verified by abundant measured data to meet actual needs ${ }^{[10]}$. Continuous optimization of the parameter combination can maximize the effectiveness of the constructed wetland. Additionally, the management of constructed wetlands also plays a very important role in its operation effect. In autumn and winter, the dead leaves would release nitrogen and phosphorus into the water due to the wilt of plants, resulting in poor removal in autumn and winter. Improving operation management and timely harvesting withered plants will greatly improve the operation efficiency of constructed wetlands in autumn and winter ${ }^{[11]}$.

\section{Conclusions}

(1) The constructed wetland project is dominated by surface-flow wetlands, with high dissolved oxygen content in the system, which is good for the nitrification and degradation of aerobic organics. The removal effect of TP is good and stable, with an average removal rate of $61.52 \%$ and a small seasonal variation. The removal of COD in spring and summer is obviously effective than that in autumn and winter. The removal rate of TN is relatively low, with higher $\mathrm{TN}$ concentration in the effluent than the influent in winter, due to the high dissolved oxygen environment in the wetland which is not conducive to denitrification.

(2) The operation effect of the constructed wetland in winter is relatively poor. In the operation and management of the project, the withered plants should be harvested in time to prevent the release of nitrogen and phosphorus and other elements from dead branches and leaves, which may cause water quality fluctuations and become a new source of pollution. The design parameters of constructed wetlands need to be continuously optimized in combination with actual needs to maximize the effectiveness of constructed wetlands.

\section{References}

1. Ministry of Water Resource of the People's Republic of China. China Water Resources Bulletin
[M]. Beijing: China Water Conservancy and Hydropower Press, 2018.

2. J. Gu, J. Zhao, Y. Wang, Z. Wang, H. Jiang, H. Zhao. Study on the effect of constructed wetland in advanced treatment for the effluent of wastewater treatment plant and nitrogen removal enhancement [J]. Modern Chemical Industry, 2020, 40(3): 64-66.

3. H. Wu, J. Zhang, et al. A review on the sustainability of constructed wetlands for wastewater treatment: Design and operation[J]. Bioresource Technology, 2015, 175:594-601.

4. J. Vymazal, Constructed wetlands for wastewater treatment[J]. Encyclopedia of Ecology,2019(1):1421.

5. L. Kong, W. Shao, R. Mei, et al. Study on constructed wetland for advanced treatment of terminal effluent of wastewater treatment plant in zhejiang province[J]. China Water and wastewater, 2019,35(2):39-42.

6. Ministry of Environmental Protection of the People's Republic of China, Editorial Board of Water and Wastewater Monitoring and Analysis Methods eds. Water and wastewater monitoring and analysis methods: 4th edition. Beijing: China Environmental Science Press, 2002.

7. S. Wang, Theory and technology of sewage treatment by constructed wetland[M]. Beijing: Science Press, 2007.

8. F. He, Z. Wu, et al. Nitrification and Denitrification in the Integrated Vertical Flow Constructed Wetlands[J]. Environmental Science, 2005, 26(1): 47-50.

9. R. Chu, N. Chen, X. Wang, et al. The nitrogen removal effect of emergent plant in constructed wetland. Environmental Pollution \& Control, 2017, 39( 8$): 884-889$.

10. K. Liang, J. Chang, F. Wang, et al. Purification ability of tail water and optimal hydraulic loading rates in vertical flow constructed wetland[J]. J Lake Sci, 2016, 28(1) : 114-123.

11. J. Huang, Q. Chen, L. Xu, Problems and countermeasures in application of constructed wetlands. Environmental Science, 2013, 34(1): 401408. 